\title{
RANCANG BANGUN PENINGKATAN PRODUKTIVITAS LAHAN SAWAH PADA KAWASAN DAS PADANG GUCI KABUPATEN KAUR
}

\author{
$\operatorname{Herwan}^{1)}$, M. Faiz Barchia ${ }^{2)}$ dan Bandi Hermawan ${ }^{2)}$ \\ 1) Program Studi Pasca Sarjana Pengelolaan Sumberdaya Alam dan Lingkungan Fakultas \\ Pertanian, Universitas Bengkulu \\ 2) Jurussan Agroteknologi, Fakultas Pertanian, Universitas Bengkulu
}

\begin{abstract}
ABSTRAK
Beras adalah komoditas strategis karena menjadi makanan pokok masyarakat Indonesia yang jumlahnya hampir mencapai 240 juta jiwa. Pertumbuhan penduduk yang tidak diimbangi dengan pertumbuhan produksi bahan pangan akan menimbulkan permasalahan pangan. Salah satu upaya yang harus dilakukan untuk mencegah timbulnya masalah ketersediaan pangan adalah mengoptimalkan penggunaan lahan pertanian dengan meningkatkan irigasi pada daerah aliran sungai sehingga indeks pertanaman dapat meningkat. Potensi pengembangan lahan pertanian tanaman pangan padi sawah yang telah dikembangkan di Kabupaten Kaur adalah seluas $7.867 \mathrm{Ha}$. Teknologi usaha tani dan pengolahan hasil, yaitu peningkatan sistem irigasi, pengelolahan tanah, pemupukan, penggunaan benih unggul, pengendalian hamapenyakit-gulma tanaman, perontokan padi, pengeringan gabah, penggilingan padi, dan lumbung padi harus dikembangkan untuk meningkatkan produktivitas lahan yang selama ini terkategori masih rendah (4,21 ton/ha) dibanding dengan produktivitas padi nasional dan potensi genetik masing-masing varietas yang ditanam pada persawahan di DAS Padang Guci. Fasilitasi peningkatan sarana-prasarana produksi dan pengolahan hasil harus ditingkatkan sesuai dengan rencana pengembangan yang disusun dalam rancang bangun peningkatan produktivitas lahan sawah di DAS Padang Guci.
\end{abstract}

Kata kunci: rancang bangun, produktivitas padi, DAS Padang Guci

\section{PENDAHULUAN}

Kebutuhan bahan pangan terutama beras akan terus meningkat sejalan dengan pertambahan jumlah penduduk dan peningkatan konsumsi per kapita akibat peningkatan pendapatan masyarakat. Beras adalah komoditas strategis karena menjadi makanan pokok (staple food) masyarakat Indonesia yang jumlahnya hampir mencapai 240 juta jiwa. Konsumsi beras per kapita Indonesia tergolong sangat besar yaitu lebih kurang $130 \mathrm{~kg} /$ tahun, sehingga kebutuhan beras nasional sangat besar (Adnyana, dkk. 2005). Ketahanan pangan akan menjadi masalah nasional, sehingga diperlukan perhatian semua pihak. Pertumbuhan penduduk yang tidak diimbangi dengan pertumbuhan produksi bahan pangan akan menimbulkan permasalahan pangan.

Upaya peningkatan produksi bahan pangan saat ini terganjal oleh berbagai kendala, seperti konversi lahan sawah subur ke penggunaan lain, penyimpangan iklim (climate anomaly), gejala kelelahan teknologi (technology fatigue), penurunan kualitas sumberdaya lahan (soil sickness) yang berdampak terhadap penurunan produktivitas (Pramono et al., 2005). Salah satu upaya yang harus dilakukan untuk mencegah timbulnya masalah ketersediaan pangan adalah mengoptimalkan penggunaan lahan pertanian dengan meningkatkan irigasi pada daerah aliran sungai sehingga indeks pertanaman 
tanaman pangan dapat meningkat. Namun, prasarana irigasi yang sangat minim membatasi usaha ekstensifikasi pengembangan lahan sawah (Subiksa, 2008).

Sektor pertanian mempunyai peranan yang sangat dominan dalam perekonomian Kabupaten Kaur dengan PDRB yang mencapai $47,27 \%$. Sektor ini menjadi tumpuan dalam penciptaan lapangan pekerjaan, dan sektor pertanian relatif lebih tahan terhadap gejolak dan krisis perekonomian. Pada Tahun 2010 jumlah penduduk Kabupaten Kaur yang bekerja di sektor pertanian sebesar $86,38 \%$ dan sebaliknya, sumbangan PDRB dari sektor pertanian hanya sebesar 47,27\%. Ini memberikan arti bahwa produktivitas kerja petani dan lahan pertanian sangat rendah dalam menopang pembangunan di Kabupaten Kaur selama ini (RPJMD, 2011).

Potensi pengembangan lahan pertanian tanaman pangan padi sawah yang telah dikembangkan di Kabupaten Kaur seluas 7.867 Ha. Dari luas lahan sawah tersebut belum ada yang telah dikembangkan dengan fasilitas irigasi teknis. Luas lahan sawah berdasarkan kualitas irigasi di Kabupaten Kaur yaitu lahan sawah irigasi $1 / 2$ teknis sebesar $795 \mathrm{Ha}$, irigasi sederhana seluas $3.136 \mathrm{Ha}$, irigasi desa non PU seluas 1.287 Ha, dan sawah tadah hujan seluas $2.642 \mathrm{Ha}$ (Dinas Pertanian Kabupaten Kaur, 2012). Kualitas fasilitas irigasi ini akan mempengaruhi tingkat produktivitas lahan sawah di Kabupaten Kaur. Produktivitas padi rata-rata di Kabupaten Kaur baru mencapai 4.2 ton/ha, jauh di bawah produktivitas padi rata-rata nasional.

Uraian latar belakang menghantarkan pada beberapa permasalahan pengembangan dalam peningkatan produktivitas lahan sawah di Kabupaten Kaur khususnya dalam kawasan DAS Padang Guci, yaitu:

1) Apakah subsistem teknologi usaha tani dan pengolahan hasil mempengaruhi produktivitas usaha tani padi pada persawahan di DAS Padang Guci?

2) Bagaimanakah proyeksi pertumbuhan produktivitas padi apabila subsistem usaha tani padi dapat difasilitasi pada persawahan di DAS Padang Guci?

3) Fasilitas apa saja yang diperlukan untuk meningkatkan produktivitas usaha tani padi pada persawahan di DAS Padang Guci?

Tujuan dari penelitian pengembangan dalam peningkatan produktivitas lahan sawah di Kabupaten Kaur khususnya dalam kawasan DAS Padang Guci, adalah:

1) Mengidentifikasi subsistem teknologi usaha tani dan pengolahan hasil mempengaruhi produktivitas usaha tani padi pada persawahan di DAS Padang Guci.

2) Menyusun proyeksi pertumbuhan produktivitas padi apabila subsistem usaha tani padi dapat difasilitasi pada persawahan di DAS Padang Guci.

3) Menyusun fasilitas yang diperlukan untuk meningkatkan produktivitas usaha tani padi di DAS Padang Guci.

\section{METODA PENELITIAN}

\section{Lokasi dan waktu}

Penelitian ini telah dilakukan dari bulan Februari-Maret 2012. Lokasi penelitian adalah wilayah DAS Padang Guci, yang meliputi Kecamatan Padang Guci Hulu, Kaur Utara, Padang Guci Hilir, dan Kecamatan Tanjung Kemuning.

\section{Pengambilan data}

Beberapa alat dan bahan yang digunakan pada penelitian ini antara lain; peta, Kamera, alat tulis, kuisioner, dan bahan lain yang dianggap perlu. Populasi dalam penelitian ini adalah masyarakat desa yang menjadi sentra produksi padi sawah berada di DAS Padang Guci. Penentuan sampel pada penelitian ini menggunakan metoda yang dikembangkan 
oleh Slovin (Kusmayadi, 2000 dalam Yuliansyah, 2008).

$$
\mathrm{n}=\frac{N}{N(d)^{2}+1}
$$

Dimana: $\mathrm{n}=$ Jumlah sampel; $\mathrm{N}=$ Jumlah populasi; dan $\mathrm{d}=$ Derajat Kepercayaan 90 $\%$ dengan tingkat kesalahan 0,2 (10\%). Mengikuti rumus di atas, maka jumlah sampel atau responden adalah:

$$
\mathrm{n}=\frac{8133}{81330,10^{2}+1}=98,78
$$

(dibulatkan menjadi 100 Responden)

Pengamatan langsung di lapangan dilakukan untuk memperoleh data dan informasi mengenai sistem irigasi, cara dan alat pengolahan tanah, varietas padi yang ditanam, cara pengendalian hama, penyakit dan gulma, jenis pupuk yang digunakan, cara dan alat perontok padi. Wawancara adalah usaha mengumpulkan informasi dengan mengajukan sejumlah pertanyaan secara lisan untuk dijawab secara lisan pula (Nawawi, 2005). Wawancara yang dilakukan berpedoman dengan kuisioner.

Data yang dikumpulkan dalam penelitian ini adalah data primer dan data sekunder. Data primer diperoleh langsung dari responden melalui wawancara yang menggunakan kuisioner yang sudah dipersiapkan terlebih dahulu. Data sekunder adalah data yang berasal dari instansi atau lembaga dan juga studi pustaka dengan cara membaca literatur yang berhubungan dengan penelitian ini.

\section{Analisis data}

Data primer dan sekunder yang diperoleh melalui penelitian ini akan dianalisis secara deskriptif dan kuantitatif dengan regresi untuk mengetahui kecenderungan hubungan antara subsistem sosial dan teknologi usaha tani dengan produktivitas lahan yang ada di wilayah DAS Padang Guci. Selanjutnya data kecenderungan produktifitas lahan digunakan untuk menyusun rancang bangun kebijakan yang terkait dengan praktek usaha tani di wilayah DAS Padang Guci pada khususnya, di Kabupaten Kaur pada umumnya.

Data produktivitas yang diperoleh melalui ekstrapolasi dan rancang bangun kebijakan untuk peningkatan produktivitas lahan sawah sebagai produk dari penelitian ini akan menjadi acuan dalam penyusunan Rencana Strategis Dinas Pertanian Kabupaten Kaur khusus yang menyangkut pengembangan produktivitas padi sawah.

\section{HASIL DAN PEMBAHASAN}

\section{Hubungan Panca Usaha Tani dengan Produktivitas Lahan}

Semua petani sawah yang terpilih di DAS Padang Guci telah menggunakan traktor tangan dalam melakukan pengolahan tanah untuk persiapan tanam padi di lahan sawahnya. Transformasi pengolahan tanah dari pola tradisional yang membajak sawah dengan cangkul dan bajak dengan tenaga hewan digantikan dengan penggunaan traktor tangan dimulai tahun 2010. Pada tahun tersebut kebanyakan kelompok tani di Provinsi Bengkulu mendapatkan bantuan traktor tangan dari Pemerintah. Jumlah traktor tangan di kawasan DAS Padang Guci tersaji seperti pada Tabel 1 .

Pengairan adalah salah satu faktor produksi pada pola usaha tani lahan sawah. Pengairan pada persawahan di DAS Padang Guci sebagian besar masih berupa pengairan yang sederhana. Sistem pengairan yang masih sederhana ini dilakukan oleh $54 \%$ petani di wilayah ini, sementara sebagian lain telah berpengairan $1 / 2$ teknis, yaitu sebanyak $46 \%$. Kurangnya pengembangan sistem pengairan untuk persawahan ini menyebabkan nilai produktivitas lahan di DAS Padang Guci masih rendah. Produktivitas lahan sangat tergantung pada pengembangan sistem pengairan. Hal ini dapat dilihat dari 
Tabel 1. Jumlah traktor tangan di DAS Padang Guci

\begin{tabular}{|c|c|c|c|c|}
\hline \multirow[t]{2}{*}{ No. } & \multirow[t]{2}{*}{ Kecamatan } & \multicolumn{3}{|c|}{$\begin{array}{c}\text { Jumlah Traktor Tangan } \\
\text { (Unit) }\end{array}$} \\
\hline & & 2009 & 2010 & 2011 \\
\hline 1. & Padang Guci Hulu & - & 15 & 15 \\
\hline 2. & Padang Guci Hilir & - & 20 & 21 \\
\hline 3. & Kaur Utara & - & 15 & 17 \\
\hline \multirow[t]{2}{*}{4.} & Tanjung Kemuning & - & 22 & 23 \\
\hline & Jumlah & 0 & 72 & 79 \\
\hline
\end{tabular}

Sumber: Dinas Pertanian Kabupaten Kaur, 2012

persamaan di bawah ini dimana dengan meningkatnya sistem pengairan maka kecenderungan akan diikuti dengan peningkatan produktivitas lahan, yaitu:

$$
\mathrm{Y}=0.377 \mathrm{X}+3.687 \quad \mathrm{R}^{2}=0.070
$$

Dimana $\mathrm{Y}=$ produktivitas lahan; $\mathrm{X}=$ sistem pengairan.

Produktivitas padi sawah ditentukan dengan penggunaan varietas unggul. Beberapa varietas unggul yang digunakan oleh petani padi di DAS Padang Guci yaitu cigelis, ciherang, invari dan IR 64. Varietas yang paling banyak digunakan oleh petani sawah di DAS Padang Guci yaitu varietas Invari, namun produktivitas varietas unggul yang mampu berproduksi paling tinggi adalah varietas Ciherang. Jenis varietas unggul dan produktivitas padi pada persawahan DAS Padang Guci disajikan pada Tabel 2.

Tabel 2. Varietas dan produktivitas padi di DAS Padang Guci

\begin{tabular}{llcc}
\hline No. & Varietas & $\begin{array}{c}\text { Jumlah } \\
\text { Petani } \\
(\%)\end{array}$ & $\begin{array}{c}\text { Produktivitas } \\
\text { (ton/ha) }\end{array}$ \\
\hline 1. & Cigelis & 17 & 3.91 \\
2. & Ciherang & 21 & 4.38 \\
3. & Invari & 48 & 4.24 \\
4 & IR 64 & 11 & 4.05 \\
\hline \multicolumn{4}{r}{ Rerata }
\end{tabular}

Sumber : Data Primer diolah, 2012

Produktivitas padi dari 4 (empat) varietas unggul yang ditanam petani di DAS Padang Guci masih rendah bila dibanding dengan potensi hasil varietas unggul secara nasional yang telah mencapai $6-7$ ton/ha. Produktivitas varietas Ciherang telah mencapai 7,46 t/ha di tingkat petani, sedangkan di tingkat Balai Benih Kurik hasilnya mencapai 8,4 t/ha (Makarim et al, 2007).

Semua petani padi di persawahan DAS Padang Guci telah melakukan pemupukan untuk meningkatkan produktivitas lahannya, tetapi jumlah pupuk yang digunakan masih rendah dan belum optimal sesuai dengan dosis anjuran umum pertanaman padi. Selain petani telah menggunakan pupuk tunggal Urea, SP36, dan $\mathrm{KCl}$, petani juga telah menggunakan pupuk majemuk Ponska. Jumlah petani berdasarkan tingkat pemakaian pupuk disajikan pada Tabel 3.

Tabel 3. Tingkat pemakaian pupuk, Urea jumlah petani, dan produktivitas padi di DAS Padang Guci

\begin{tabular}{llcc}
\hline No. & $\begin{array}{l}\text { Pemupukan } \\
\text { Urea } \\
\text { (kg/ha) }\end{array}$ & $\begin{array}{c}\text { Jumlah } \\
\text { Petani } \\
(\%)\end{array}$ & $\begin{array}{c}\text { Produktivitas } \\
\text { (ton/ha) }\end{array}$ \\
\hline 1. & 100 & 38 & 4.28 \\
2. & 150 & 43 & 4.21 \\
3. & 200 & 16 & 4.19 \\
\hline
\end{tabular}

Sumber : Data Primer diolah, 2012.

Sebagian besar petani sawah di DAS Padang Guci menggunakan pupuk Urea sebanyak $150 \mathrm{~kg} / \mathrm{ha}$, walaupun tingkat produktivitas padi sawah dengan tingkat pemupukan $100-200 \mathrm{~kg} / \mathrm{ha}$ tidak menunjukkan perbedaan yang nyata, bahkan dengan semakin meningkatnya jumlah pupuk yang diberikan, produktivitas lahan semakin menurun.

Petani sawah di DAS Padang Guci umumnya menggunakan pupuk $\mathrm{P}$ dalam 
bentuk SP36. Petani sawah di wilayah ini menggunakan pupuk SP36 dalam jumlah yang sama untuk meningkatkan kesuburan tanahnya. Jumlah pupuk SP36 yang diberikan dengan dosis $100 \mathrm{~kg} / \mathrm{ha}$, dan rata-rata produktivitas padi sebesar 4.23 ton/ha.

Tingkat pemakaian pupuk $\mathrm{KCl}$ oleh petani sawah di DAS Padang Guci berkisar antara $75-100 \mathrm{~kg} / \mathrm{ha}$, tetapi sebagian besar petani di wilayah ini menggunakan pupuk sebesar $75 \mathrm{~kg} \mathrm{KCl} / \mathrm{ha}$. Petani yang menggunakan pupuk $\mathrm{KCl}$ dengan dosis sebesar ini sebanyak $67 \%$, sementara yang menggunakan dosis $100 \mathrm{~kg} \quad \mathrm{KCl} / \mathrm{ha}$ sebanyak $33 \%$ dari petani sawah di wilayah ini. Pemakaian pupuk $\mathrm{KCl}$ dengan dosis $75 \mathrm{~kg} / \mathrm{ha}$ mampu memberikan produktivitas padi sebesar 4.26 ton/ha, dan lebih tinggi dibandingkan dengan dosis pupuk $\mathrm{KCl}$ sebesar $100 \mathrm{~kg} / \mathrm{ha}$ yang hanya mampu memberikan produktivitas hanya 4.17 ton/ha. Tingkat pemakaian pupuk $\mathrm{KCl}$ dan produktivita padi disajikan pada Tabel 4.

Tabel 4. Tingkat pemakaian pupuk KCl, jumlah petani, dan produktivitas padi di DAS Padang Guci.

\begin{tabular}{llcc}
\hline No. & $\begin{array}{l}\text { Pemupukan } \\
\mathrm{KCl} \\
(\mathrm{kg} / \mathrm{ha})\end{array}$ & $\begin{array}{c}\text { Jumlah } \\
\text { Petani } \\
(\%)\end{array}$ & $\begin{array}{c}\text { Produktivitas } \\
\text { (ton/ha) }\end{array}$ \\
\hline 1. & 75 & 67 & 4.26 \\
2. & 100 & 33 & 4.17 \\
\hline
\end{tabular}

Sumber: Data Primer diolah, 2012.

Tingkat pemakaian pupuk Ponska oleh petani sawah DAS Padang Guci cukup tinggi, yaitu berkisar antara $150-200$ $\mathrm{kg} / \mathrm{ha}$, dan sebanyak $58 \%$ petani pada wilayah ini menggunakan dosis sebesar $200 \mathrm{~kg} / \mathrm{ha}$. Produktivitas padi sawah pada tingkat dosis ini lebih rendah disbanding dengan pemberikan pupuk Ponska dengan dosis $150 \mathrm{~kg} / \mathrm{ha}$. Tingkat produktivitas padi dan jumlah pemakai pupuk Ponska disajikan pada Tabel 5. Produktivitas padi dengan pemakaian pupuk Ponska sebesar $150 \mathrm{~kg} / \mathrm{ha}$ mampu memberikan produksi sebesar 4.26 ton/ha.
Tabel 5. Tingkat pemakaian pupuk Ponska, jumlah petani, dan produktivitas padi di DAS Padang Guci.

\begin{tabular}{llcc}
\hline No. & $\begin{array}{l}\text { Pemupukan } \\
\text { Ponska } \\
(\mathrm{kg} / \mathrm{ha})\end{array}$ & $\begin{array}{c}\text { Jumlah } \\
\text { Petani } \\
(\%)\end{array}$ & $\begin{array}{c}\text { Produktivitas } \\
\text { (ton/ha) }\end{array}$ \\
\hline 1. & 150 & 58 & 4.26 \\
2. & 200 & 42 & 4.20 \\
\hline
\end{tabular}

Sumber: Data Primer diolah, 2012.

Semua petani sawah di kawasan DAS Padang Guci telah menggunakan bahan kimia pertanian untuk pengendalian hama dan penyakit tanaman. Senyawa kimia yang digunakan disesuaikan dengan gejala dan jenis hama dan penyakit yang menyerang tanaman padi.

Semua petani sawah di kawasan DAS Padang Guci telah menggunakan power threser saat perontokan gabah padi. Alat perontok padi ini bersifat portable, sehingga memudahkan petani melakukan perontokan gabah padi. Alat ini di bawah ke tengah sawah, dan sisa panen tetap ditinggal di petakan sawah. Perlakukan ini sangat baik karena dapat mengurangi hasil panen ke luar dari wilayah produksinya. Bahan organik sisa panen dapat dipergunakan kembali sebagai pupuk organik. Penggunaan power threser juga dapat mengatasi kekurangan tenaga kerja keluarga sehingga pekerjaan perontokan gabah dapat lebih cepat. Perontokan gabah dengan menggunakan power threser juga dapat mengurangi kehilangan gabah hasil panen akibat tercecer saat pengangkutan. Penggunaan power threser dalam perontokan gabah padi menjadikan pekerjaan bagi keluarga petani menjadi lebih efektif, efisien, dan tepat guna.

\section{Produksi Padi dalam Kawasan DAS Padang Guci}

Terdapat perbedaan produksi yang cukup signifikan antara lahan sawah irigasi di kawasan DAS Sungai Padang Guci dengan lahan sawah tanpa irigasi, seperti halnya terjadi di Kecamatan Padang Guci Hulu, Padang Guci Hilir dan Kaur Utara panen dapat dilakukan 2 kali dalam 1 tahun. Sedangkan di Kecamatan Tanjung 
Kemuning yang belum dilalui oleh saluran irigasi, petani secara bergotong royong membuat saluran irigasi dari DAS Padang Guci secara manual dengan menyusun batu-batu sungai membentuk suatu pola yang dapat mengalirkan air sungai DAS Padang Guci ke lahan sawah mereka dengan panen atau musim tanam yang masih tergantung pada musim. Fluktuasi produksi pada dalam kawasan DAS Padang Guci antara tahun 2009 sampai 2011 dapat dilihat pada Tabel 6.

Produksi padi dari kawasan DAS Padang Guci pada tahun 2010 cukup tinggi yaitu 18.253 ton.

\section{Rancang Bangun Peningkatan Produksi Padi \\ Potensi Produksi Padi}

\section{1) Potensi Produksi Saat Ini}

Rancang bangun produksi padi di wilayah DAS Padang Guci diarahkan untuk meningkatkan pertumbuhan konsumsi di luar DAS Padang Guci. Rancang bangun peningkatan produksi padi ini terutama melalui peningkatan produktivitas lahan. Luas lahan sawah menurut system irigasi dalam kawasan

Berdasarkan Tabel 7 bahwa luas sawah yang ditanam 2 kali dalam setahun adalah lahan sawah yang telah memiliki irigasi, baik irigasi $1 / 2$ teknis, irigasi sederhana, maupun irigasi desa non PU, sementara pada persawahan tadah hujan baru dapat ditanam 1 kali dalam setahun. Lahan sawah dalam kawasan DAS Padang Guci umumnya telah memiliki indeks pertanaman (IP) sebesar 200 pada lahan seluas $1.823 \mathrm{Ha}$, baik itu pada irigasi $1 / 2$ teknis, irigasi sederhana, dan irigasi desa non PU, sementara pada lahan sawah tadah hujan hanya memiliki indeks pertanaman sebesar 100 dengan luas lahan sebesar 633 Ha. Berdasarkan luas lahan dan indeks pertanaman serta rata-rata produktivitas padi dalam kawasan DAS Padang Guci sebesar 4.21 ton/ha maka diproyeksikan produksi padi rata-rata dari seluruh luas lahan sawah di DAS Padang Guci sebesar 18.090 ton. Potensi produksi berdasarkan rata-rata produktivitas lahan saat ini seperti pada Tabel 8.

Tabel 6. Produksi padi dalam kawasan DAS Padang Guci

\begin{tabular}{|c|c|c|c|c|c|c|}
\hline No. & Kecamatan & & $\begin{array}{l}\text { Produksi* } \\
\text { (ton) }\end{array}$ & & $\begin{array}{l}\text { Kebutuhan** } \\
\text { (ton) }\end{array}$ & Keterangan \\
\hline & & 2009 & 2010 & 2011 & & \\
\hline 1. & $\begin{array}{l}\text { Tanjung } \\
\text { Kemuning }\end{array}$ & 4.061 & 4.717 & 1.369 & 1.324 & Swa-sembada \\
\hline 2. & Kaur Utara & 2.860 & 5.111 & 3.095 & 808 & Swa-sembada \\
\hline 3. & $\begin{array}{l}\text { Padang Guci } \\
\text { Hilir }\end{array}$ & 4.208 & 4.011 & 3.120 & 452 & Swa-sembada \\
\hline 4. & $\begin{array}{l}\text { Padang Guci } \\
\text { Hulu }\end{array}$ & 5.073 & 4.414 & 2.184 & 835 & Swa-sembada \\
\hline & Jumlah & 16.202 & 18.253 & 9.768 & 3.419 & Swa-sembada \\
\hline
\end{tabular}

Sumber: *Dinas Pertanian Kabupaten Kaur, 2012;** Data Primer diolah, 2012.

Tabel 7. Luas sawah berdasarkan sistem irigasi di DAS Padang Guci

\begin{tabular}{|c|c|c|c|c|c|c|}
\hline \multirow{3}{*}{ No. } & \multirow{3}{*}{ Kecamatan } & \multicolumn{4}{|c|}{ Irigasi (Ha) } & \multirow[b]{3}{*}{$\begin{array}{l}\text { Jumlah } \\
\text { (Ha) }\end{array}$} \\
\hline & & $1 / 2$ Teknis & Sederhana & Desa Non PU & Tadah Hujan & \\
\hline & & Tanam $2 \mathrm{x}$ & Tanam $2 x$ & Tanam $2 \mathrm{x}$ & Tanam 1x & \\
\hline 1. & Tanjung Kemuning & 145 & - & 38 & 457 & 640 \\
\hline 2. & Kaur Utara & - & 485 & 48 & 59 & 592 \\
\hline 3. & Padang Guci Hilir & - & 641 & 38 & 16 & 695 \\
\hline 4. & Padang Guci Hulu & - & 437 & - & 101 & 538 \\
\hline \multicolumn{2}{|r|}{ Jumlah } & 145 & 1.563 & 124 & 633 & 2.465 \\
\hline
\end{tabular}

Sumber: Dinas Pertanian Kabupaten Kaur, 2012 
Dari Tabel 8 dimana potensi produksi dari persawahan DAS Padang Guci didasarkan pada rerata produktivitas petani saat ini sebesar 4.21 ton/ha maka produksi padi dari kawasan ini sebesar 18.090 ton/ha mendekati produksi padi yang terjadi pada tahun 2010 yaitu sebesar 18.252 ton.

\section{2) Potensi Produksi Intensifikasi}

Peluang untuk meningkatkan produksi padi dari persawahan di wilayah DAS Padang Guci masih sangat besar. Lahan yang memiliki indeks pertanaman 200 dapat ditingkatkan menjadi indeks pertanaman 300 dan dari lahan yang memiliki indeks pertanaman 100 menjadi lahan yang memiliki indeks pertanaman 200. Juga upaya peningkatan intensifikasi dari tingkat produktivitas rata-rata sebesar 4.21 ton/ha menjadi $6-7$ ton/ha merupakan peluang untuk meningkatkan produksi padi dari wilayah ini.

Potensi sawah tadah hujan yang memiliki indeks pertanaman 100 atau baru melakukan penanaman $1 \mathrm{x}$ dalam setahun dapat ditingkatkan menjadi indeks pertanaman 200 dengan melakukan penanaman $2 x$ setahun. Hal ini dapat dilakukan apabila ada potensi sumberdaya air dan memberikan fasilitas irigasi pada lahan sawah tadah hujan yang mencapai $633 \mathrm{Ha}$. Apabila dilakukan pemberian fasilitas irigasi secara bertahap dengan meningkatkan pengairan irigasi seluas 150 $\mathrm{Ha}$ /tahun sehingga terjadi penambahan luas tanam $2 \mathrm{x}$ setahun dari lahan sawah tadah hujan. Untuk mengembangkan sawah tadah hujan seluas $633 \mathrm{Ha}$ menjadi lahan sawah beririgasi membutuhkan waktu selama 5 tahun, dan tentunya akan diikuti oleh peningkatan produksi padi pada wilayah ini. Proyeksi pertumbuhan produksi padi dengan adanya peningkatan luas tanam $2 \mathrm{x}$ setahun pada lahan tadah hujan seluas 150 Ha setiap tahun seperti pada Tabel 9.

Apabila peningkatan sawah irigasi seluas 150 Ha setiap tahun dari sawah tadah hujan dimana ada penambahan lahan sawah yang dapat ditanam $2 \mathrm{x}$ setahun seluas150 Ha, maka akan terjadi peningkatan produksi padi sebesar 3.49\% di wilayah DAS Padang Guci. Peningkatan produksi ini jauh melebihi laju pertumbuhan penduduk di wilayah ini yaitu rata-rata $1.69 \%$.

Produktivitas padi di tingkat petani

Tabel 8. Potensi produksi padi berdasarkan rerata produktivitas lahan saat ini di DAS Padang Guci

\begin{tabular}{llccccc}
\hline No. & Kecamatan & $\begin{array}{c}\text { Luas Sawah } \\
\text { Irigasi } \\
(\mathrm{Ha})\end{array}$ & $\begin{array}{c}\text { Produksi } \\
2 \mathrm{x} \\
\text { (ton) }\end{array}$ & $\begin{array}{c}\text { Luas Sawah } \\
\text { Tadah Hujan }\end{array}$ & $\begin{array}{c}\text { Produksi } \\
1 \mathrm{x} \\
\text { (ton) }\end{array}$ & $\begin{array}{c}\text { Total } \\
\text { Produksi } \\
\text { (ton) }\end{array}$ \\
\hline 1, & Tanjung Kemuning & 183 & 1.541 & 457 & 1.924 & 3.465 \\
2. & Kaur Utara & 533 & 4.488 & 59 & 248 & 4.736 \\
3. & Padang Guci Hilir & 679 & 5.717 & 16 & 67 & 5.785 \\
4. & Padang Guci Hulu & 437 & 3.680 & 101 & 425 & 4.105 \\
\hline & & 1.832 & 15.425 & 633 & 2.665 & 18.090 \\
\hline
\end{tabular}

Sumber: Data Primer diolah, 2012

Tabel 9. Potensi produksi padi dengan peningkatan irigasi 150 Ha setiap tahun pada sawah tadah hujan.

\begin{tabular}{|c|c|c|c|c|c|c|}
\hline No. & Tahun & $\begin{array}{l}\text { Luas Sawah } \\
\text { Irigasi } \\
\text { (Ha) }\end{array}$ & $\begin{array}{c}\text { Produksi } \\
2 \mathrm{x} \\
\text { (ton) }\end{array}$ & $\begin{array}{l}\text { Luas Sawah } \\
\text { Tadah Hujan }\end{array}$ & $\begin{array}{c}\text { Produksi } \\
1 \mathrm{x} \\
\text { (ton) }\end{array}$ & $\begin{array}{c}\text { Total } \\
\text { Produksi } \\
\text { (ton) }\end{array}$ \\
\hline 1, & 2012 & 1.832 & 15.425 & 633 & 2.665 & 18.090 \\
\hline 2. & 2013 & 1.982 & 16.688 & 483 & 2.033 & 18.721 \\
\hline 3. & 2014 & 2.132 & 17.591 & 333 & 1.401 & 19.353 \\
\hline 4. & 2015 & 2.282 & 19.214 & 183 & 770 & 19.984 \\
\hline 5 & 2016 & 2.432 & 20.447 & 33 & 138 & 20.616 \\
\hline 6 & 2017 & 2.465 & 20.775 & 0 & 0 & 20.755 \\
\hline
\end{tabular}

Sumber: Data Primer diolah, 2012 
perorangan sangat beragam dimana ada produktivitas $4.5,5,0$ dan 5.5 ton/ha. Ini menunjukkan bahwa potensi peningkatan produksi berdasarkan produktivitas saat ini masih dapat dilakukan dengan perbaikan teknologi intensifikasi, seperti perbaikan varietas, irigasi. Proyeksi peningkatan produksi dengan peningkatan produktivitas 4.5 ton/ha seperti pada Tabel 10.

Dari Tabel 10 terlihat bahwa dengan intensifikasi penanaman padi melalui beragam tindakan usaha tani dan diproyeksikan produktivitas padi saat ini sebesar 4.21 ton/ha dapat ditingkatkan menjadi 4.50 ton/ha, maka peningkatan produksi pada tahun-tahun selanjutnya dengan perbaikan irigasi dan produktivitas menjadi rata-rata sebesar $3.37 \%$ setiap tahunnya. Peningkatan produksi ini juga akan melebihi dibandingkan dengan peningkatan kebutuhan beras akibat pertumbuhan penduduk di wilayah ini.

Dari Tabel 310 juga terlihat bahwa dengan peningkatan irigasi seluas 150 $\mathrm{Ha} /$ tahun dan peningkatan produktivitas dari 4.21 ton/ha menjadi 4.50 ton/ha, maka akan terjadi peningkatan produksi sebesar $10.62 \%$ dibanding dengan kemampuan produksi saat ini. Selanjutnya secara singkat sasaran, dan kebijakan dalam rancang bangun peningkatan produktivitas padi di kawasan persawahan DAS Padang Guci tahun 2012 - 2017 disederhanakan sepeti tersaji pada Tabel 11 .

Tabel 10. Potensi produksi padi dengan peningkatan irigasi 150 Ha setiap pada sawah tadah hujan dengan produktivitas 4.5 ton/ha

\begin{tabular}{lcccccc}
\hline No. & Tahun & $\begin{array}{c}\text { Luas Sawah } \\
\text { Irigasi } \\
\text { (Ha) }\end{array}$ & $\begin{array}{c}\text { Produksi } \\
2 \mathrm{x} \\
\text { (ton) }\end{array}$ & $\begin{array}{c}\text { Luas Sawah } \\
\text { Tadah Hujan }\end{array}$ & $\begin{array}{c}\text { Produksi } \\
1 \mathrm{x} \\
\text { (ton) }\end{array}$ & $\begin{array}{c}\text { Total } \\
\text { Produksi } \\
\text { (ton) }\end{array}$ \\
\hline 1, & 2012 & 1.832 & 15.425 & 633 & 2.665 & 18.090 \\
2. & 2013 & 1.982 & 17.838 & 483 & 2.174 & 20.012 \\
3. & 2014 & 2.132 & 19.188 & 333 & 1.499 & 20.687 \\
4. & 2015 & 2.282 & 20.538 & 183 & 824 & 21.362 \\
5 & 2016 & 2.432 & 21.888 & 33 & 149 & 22.036 \\
6 & 2017 & 2.465 & 22.185 & 0 & 0 & 22.185 \\
\hline
\end{tabular}

Sumber: Data Primer diolah, 2012

Tabel 11. Sasaran, dan kebijakan dalam rancang bangun peningkatan produktivitas padi di kawasan persawahan DAS Padang Guci tahun 2012 - 2017

\begin{tabular}{|c|c|c|c|c|c|c|c|c|}
\hline \multirow[t]{2}{*}{ Sasaran } & \multirow[t]{2}{*}{ Kebijakan } & \multicolumn{6}{|c|}{ Pelaksanaan } & \multirow[t]{2}{*}{ Pelaku } \\
\hline & & 2012 & 2013 & 2014 & 2015 & 2016 & 2017 & \\
\hline \multirow[t]{4}{*}{$\begin{array}{l}\text { Subsistem } \\
\text { Usaha tani }\end{array}$} & \begin{tabular}{ll}
\multicolumn{3}{l}{ Intensifikasi irigasi } & \\
- Tadah hujan menjadi \\
irigasi desa & \\
- Irigasi desa menjadi \\
irigasi PU
\end{tabular} & $\begin{array}{l}\mathrm{x} \\
\mathrm{x}\end{array}$ & $\begin{array}{l}\mathrm{x} \\
\mathrm{x}\end{array}$ & $\begin{array}{l}\mathrm{x} \\
\mathrm{x}\end{array}$ & $\begin{array}{l}\mathrm{x} \\
\mathrm{x}\end{array}$ & $\begin{array}{l}\mathrm{X} \\
\mathrm{X}\end{array}$ & $\begin{array}{l}\mathrm{x} \\
\mathrm{x}\end{array}$ & $\begin{array}{l}\text { Dinas Pertanian } \\
\text { Dinas PU } \\
\text { Kelompok Tani }\end{array}$ \\
\hline & $\begin{array}{l}\text { Pengolahan Tanah } \\
\text { - Pemeliharaan traktor } \\
\text { tangan } \\
\text { - Peningkatan indeks } \\
\text { pertanaman }\end{array}$ & $\begin{array}{l}\mathrm{x} \\
\mathrm{x}\end{array}$ & $\begin{array}{l}\mathrm{X} \\
\mathrm{X}\end{array}$ & $\begin{array}{l}\mathrm{X} \\
\mathrm{X}\end{array}$ & $\begin{array}{l}\mathrm{X} \\
\mathrm{X}\end{array}$ & $\begin{array}{l}\mathrm{X} \\
\mathrm{X}\end{array}$ & $\begin{array}{l}\mathrm{X} \\
\mathrm{X}\end{array}$ & $\begin{array}{l}\text { Dinas Pertanian } \\
\text { Kelompok } \\
\text { Tani }\end{array}$ \\
\hline & $\begin{array}{l}\text { Benih Unggul: } \\
\text { - Pemilihan benih unggul } \\
\text { dengan produktivitas } \\
\text { tertinggi } \\
\text { - Pembinaan Penangkar } \\
\text { benih unggul } \\
\text { - Pengadaan benih unggul }\end{array}$ & $\begin{array}{l}\mathrm{x} \\
\mathrm{x} \\
\mathrm{x}\end{array}$ & $\begin{array}{l}\mathrm{x} \\
\mathrm{x} \\
\mathrm{x}\end{array}$ & $\begin{array}{l}\mathrm{x} \\
\mathrm{x}\end{array}$ & $\begin{array}{l}\mathrm{x} \\
\mathrm{x}\end{array}$ & $\begin{array}{l}\mathrm{x} \\
\mathrm{x}\end{array}$ & $\begin{array}{l}\mathrm{x} \\
\mathrm{x}\end{array}$ & $\begin{array}{l}\text { Dinas Pertanian } \\
\text { BPSB }\end{array}$ \\
\hline & $\begin{array}{l}\text { Pemupukan: } \\
\text { - Uji pemupukan spesifik } \\
\text { lokasi } \\
\text { - Penerapan pemupukan } \\
\text { spesifik lokasi } \\
\text { - Pengadaan pupuk }\end{array}$ & $\mathrm{x}$ & $\begin{array}{l}\mathrm{x} \\
\mathrm{x} \\
\mathrm{x}\end{array}$ & $\begin{array}{l}\mathrm{x} \\
\mathrm{x}\end{array}$ & $\begin{array}{l}\mathrm{x} \\
\mathrm{x}\end{array}$ & $\begin{array}{l}\mathrm{x} \\
\mathrm{x}\end{array}$ & $\begin{array}{l}\mathrm{x} \\
\mathrm{x}\end{array}$ & $\begin{array}{l}\text { Dinas Pertanian } \\
\text { BP4K }\end{array}$ \\
\hline
\end{tabular}




\begin{tabular}{|c|c|c|c|c|c|c|c|c|}
\hline & $\begin{array}{l}\text { Pengendalian Hama dan } \\
\text { Penyakit: } \\
\text { - Pengawasan gejala } \\
\text { serangan hama dan } \\
\text { penyakit tanaman. } \\
\text { - Penyediaan Saprotan } \\
\text { - } \begin{array}{l}\text { Penumbuhan } \\
\text { saprotan kios }\end{array} \\
\end{array}$ & $\begin{array}{l}\mathrm{x} \\
\mathrm{x}\end{array}$ & $\begin{array}{l}\mathrm{x} \\
\mathrm{x}\end{array}$ & $\begin{array}{l}x \\
x\end{array}$ & $\begin{array}{l}\mathrm{x} \\
\mathrm{x}\end{array}$ & $\begin{array}{l}\mathrm{x} \\
\mathrm{x}\end{array}$ & $\begin{array}{l}\mathrm{x} \\
\mathrm{x}\end{array}$ & $\begin{array}{l}\text { Dinas Pertanian } \\
\text { Disperindagkop }\end{array}$ \\
\hline $\begin{array}{l}\text { Subsistem } \\
\text { Pengolahan } \\
\text { Hasil }\end{array}$ & $\begin{array}{l}\text { Perontokan, Pengeringan dan } \\
\text { penggilingan padi: } \\
\text { - Pemeliharaan dan } \\
\text { pengadaan power threser } \\
\text { - } \text { Fasilitasi lantai jemur } \\
\text { - Pengadaan RMU } \\
\text { - Penguatan teknologi } \\
\quad \text { lumbung pangan } \\
\end{array}$ & $\begin{array}{l}\mathrm{x} \\
\mathrm{x}\end{array}$ & $\begin{array}{l}\mathrm{x} \\
\mathrm{x} \\
\mathrm{x}\end{array}$ & $\begin{array}{l}\mathrm{x} \\
\mathrm{x} \\
\mathrm{x}\end{array}$ & $\begin{array}{l}\mathrm{x} \\
\mathrm{x} \\
\mathrm{x}\end{array}$ & $\begin{array}{l}\mathrm{x} \\
\mathrm{x} \\
\mathrm{x}\end{array}$ & $\begin{array}{l}\mathrm{x} \\
\mathrm{x} \\
\mathrm{x}\end{array}$ & $\begin{array}{l}\text { Dinas Pertanian } \\
\text { Kelompok Tani }\end{array}$ \\
\hline \multirow[t]{2}{*}{$\begin{array}{l}\text { Subsistem } \\
\text { Pendukung }\end{array}$} & $\begin{array}{l}\text { SDM : } \\
\text { Pengembangan SDM petani } \\
\text { dan PPL }\end{array}$ & $\mathrm{x}$ & $\mathrm{x}$ & $\mathrm{x}$ & $\mathrm{x}$ & $\mathrm{X}$ & $\mathrm{x}$ & BP4K \\
\hline & $\begin{array}{l}\text { Pengembangan } \\
\text { Kelembagaan: } \\
\text { - } \quad \text { SDM Kelompok Tani } \\
\text { - Penguatan managemen } \\
\text { kelembagaan KT }\end{array}$ & $\begin{array}{l}\mathrm{x} \\
\mathrm{x}\end{array}$ & $\begin{array}{l}x \\
x\end{array}$ & $\begin{array}{l}x \\
x\end{array}$ & $\begin{array}{l}x \\
x\end{array}$ & $\begin{array}{l}\mathrm{x} \\
\mathrm{x}\end{array}$ & $\begin{array}{l}\mathrm{x} \\
\mathrm{x}\end{array}$ & $\begin{array}{l}\text { Dinas Pertanian } \\
\text { BP4K }\end{array}$ \\
\hline
\end{tabular}

\section{KESIMPULAN}

Teknologi usaha tani dan pengolahan hasil, yaitu peningkatan sistem irigasi, pengelolahan tanah, pemupukan, penggunaan benih unggul, pengendalian hama-penyakit-gulma tanaman, perontokan padi, pengeringan gabah, penggilingan padi, dan lumbung padi harus dikembangkan untuk meningkatkan produktivitas lahan yang selama ini terkategori masih rendah dibanding dengan produktivitas padi nasional dan potensi genetik masing-masing varietas yang ditanam pada persawahan di DAS Padang Guci.

Fasilitasi peningkatan kualitas sumberdaya manusia dan sarana-prasarana produksi dan pengolahan hasil harus ditingkatkan sesuai dengan rencana pengembangan yang disusun dalam rancang bangun peningkatan produktivitas lahan sawah di DAS Padang Guci.

\section{DAFTAR PUSTAKA}

Adnyana, M.O., I G.M. Subiksa, H. Pane, dan D.K.S. Swastika. 2005. Arah dan Prospek Pengembangan
Tanaman Pangan di Lahan Rawa. Pusat Penelitian dan Pengembangan Tanaman Pangan. Badan Litbang Pertanian.

Dinas Pertanian Kabupaten Kaur. 2012. Statistik Pertanian Kabupaten Kaur 2011. Bintuhan.

Makarim, A.K., M. Oka A., I G.M. Subiksa, dan Adiwijono. 2007. Model Pengembangan Lumbung Pangan di Kawasan Timur Indonesia: Merauke, Seram dan Buru. Pusat Penelitian dan Pengembangan Tanaman Pangan, Badan Litbang Pertanian.

Pramono, J., S. Kartaatmadja, dan H. Supadmo. 2001. Efisiensi Pemanfaatan Sumberdaya pada Usahatani Padi Sawah di Kab. Sragen, Jawa Tengah. Makalah Seminar Nasional Pengembangan Teknologi Pertanian. Mataram, 30 - 31 Oktober 2001.

Promono, dkk. 2005. Upaya Peningkatan Produksi Padi Sawah Melalui pendekatan Pengelolaan Tanaman dan Sumberdaya Terpadu. Jurnal Agrosains 7 (1) : 1-6.

RPJMD Kabupaten Kaur. 2011. Rencana Pembangunan Jangka Menengah 
Daerah Kabupaten Kaur. 2011. Bintuhan.

Subiksa, I. G. M. 2008. Prospek Pengembangan Rice Estate di Kabupaten Merauke: Tinjauan dari Aspek Pengelolaan Tanah dan Air. Jurnal Sumberdaya Lahan Vol. 2 No. 2, Desember 2008

Subiksa, I G.M. dan N.P.S. Ratmini. 2008. Pengaruh kapur dan fosfat alam terhadap pertumbuhan dan produksi padi pada lahan sulfat masam Telang Sumatera Selatan. Paper pada Pertemuan Ilmiah Tahunan HITI di Sumatera Selatan (Unpublished).

Yuliansyah, A. 2008. Pengembangan Kawasan Wisata Pantai Panjang dan Pantai Nala Bengkulu. Skripsi Jurusan Perencanaan Wilayah Fakultas Teknik Universitas Brawijaya.Malang 